\title{
Psikolojik Sermayenin Girişimci Olma Eğilimine Etkisi: KOSGEB Girişimcilik Eğitimine Katılan Kursiyerler Üzerine Bir Araştırma ${ }^{1}$
}

\author{
DOI: $10.26466 /$ opus.587988
}

*

\section{Vasfi Kahya*}

* Dr. Öğr. Üyesi, Dumlupınar Üniversitesi, Hisarcık MYO/ Yönetim ve Org. Böl, Kütahya / Türkiye E-Posta: vasfi.kahya@dpu.edu.tr

ORCID: $\underline{0000-0002-2154-5689}$

Öz

Girişimcilik literatürüne bakıldığında daha çok girişimci özelliklerinin üzerinde durulduğu dikkat çekmektedir. Psikolojik sermaye kavramı, günümüz çalışma hayatının gelişimi için insan kaynağının üstün yönleri ve psikolojik kapasiteleri üzerinde yapılan çalışmalar sonucunda ortaya çıkmış pozitif yönelimli bir kavramdır. Bu çalışmada, KOSGEB Girişimcilik eğitimine katılan kursiyerlerin psikolojik sermaye seviyelerini tespit ederek bu değgişkenin girişimci olmaya etkisi araştırılmıştır. Yapılan çalışmalar neticesinde katılımcıların sadece \%10'unun bir işletme kurmaya yöneldiği görrülmüştür. Psikolojik sermayesi yüksek bireylerin zorluklara daha fazla göğ̈̈s gereceğinden girişimci olma isteğinin daha yüksek olması beklenmektedir. Psikolojik sermaye; iyimserlik, umut, öz yeterlilik ve dayanıklılık açısından 4 boyutta incelenecektir. Araştırmanın katılımcıları KOSGEB girişimcilik eğitimi almış bireylerden oluşmaktadır. Verilerin analizi için çoklu regresyon yöntemi kullanılmıştır. Elde edilen bulgular, hem bazı demografik özelliklerin hem de psikolojik sermaye alt boyutlarından öz yeterlilik ve umudun çalışanların girişimci olma yönündeki niyetlerini etkilediğini göstermektedir. Buna göre, dayanıklllk ve iyimserlik girişimcilik niyetini anlaml olarak etkilemezken, öz yeterlilik ve umut boyutlar girişimcilik niyetini anlaml ve pozitif olarak etkilemektedir.

Anahtar Kelimeler: KOSGEB, Girişimcilik Eğitimi, Psikolojik Sermaye

\footnotetext{
${ }^{1}$ Bu çalışma, 2-4 Mayıs tarihleri arasında düzenlenen 18. Uluslararası Iş̧letmecilik Kongresi'nde sunulmuş olan bildirinin genişletilmiş halidir.
} 


\title{
The Effect of Psychological Capital on Entrepreneurial Tendency: A Research on Trainees Attended to KOSGEB Entrepreneurship Education
}

\begin{abstract}
When the entrepreneurship literature is examined, it is noteworthy that entrepreneur characteristics are emphasized. The concept of psychological capital is a positive-oriented concept emerged as a result of studies on the superior aspects and psychological capacities of human resources for the development of today's working life. In this study, the effect of this variable on entrepreneurship was determined by evaluating the psychological capital levels of the trainees participating in KOSGEB Entrepreneurship training. As a result of the studies, only $10 \%$ of the participants show that they are aiming to establish a new venture. It is expected that the individuals with high psychological capital will be more likely to face difficulties and their desire to be an entrepreneur is higher. Psychological capital will be examined in 4 dimensions; optimism, hope, self-efficacy and durability. The participants of the study will be the attendances of the KOSGEB entrepreneurship education. Multiple regression method will be used for data analysis. The findings show that both self-efficacy and hope from some demographic characteristics and psychological capital sub-dimensions affect the intentions of employees to be entrepreneurs. Accordingly, while durability and optimism do not significantly affect the intention of entrepreneurship, self-efficacy and hope dimensions affect the entrepreneurship intention positively and positively.
\end{abstract}

Keywords: KOSGEB, Entrepreneurship Education, Psychological Capital 


\section{Giriş}

Girişimcilik olgusu ülkemizdeki ekonomik gelişme için oldukça hayati öneme sahiptir. Girişimcilik alanındaki önemli konulardan birisi olan girişimcilik eğitimi aslında uzun yıllardır gündemde olan ve uygulanan bir yaklaşım olmasına rağmen, ülkemizde özellikle 2000'li yıllardan itibaren yaygınlaşmaya başlamıştır. Bu süreçte birçok faktör, girişimcilik eğitiminin gelişmesine katkıda bulunmuştur. Bu faktörler arasında, özellikle sivil toplum kuruluşlarının, hükümetlerin ve ilgili kuruluşların, özellikle de Üniversitelerin, Bakanlıkların ve KOSGEB'in katkılarından bahsedilebilir. Sivil toplum kuruluşlarının, girişimcilik konusunda farkındalığı artırması özellikle son yıllarda etkili olmuştur. Bunun yanında, üniversitelerde verilen girişimcilik dersleri ve girişimcilik eğitimlerinin yanında birçok özel ve kamu kuruluşunun uygulamalı girişimcilik eğitimi vermesi, girişimcilik örneklerinin artmasına yol açmıştır. Bu bağlamda girişimci üniversitelerin sayılarındaki artışla birlikte girişimcilik eğitimi de paralel bir şekilde yaygınlaşmış ve son yıllarda girişimci sayısı artmaya devam etmiştir (Özdemir, 2017, s.3). Burada özellikle bu işle doğrudan görevlendirilen KOSGEB koordinatörlüğünde yürütülen uygulamalı girişimcilik eğitimlerinden bahsetmekte fayda bulunmaktadır. KOSGEB'in önemli görev alanlarından bir tanesi vatandaşlara küçük ve orta düzeyde girişimcilerde bulunmaları sürecinde farklı yönlerden destek olmaktır. Bu desteklerin içerisinde mevcut girişimcilere sağlanan hibe, proje ve danışmanlık hizmetleri yanında girişimci adaylarına sağlanan hibe ve danışmanlık hizmetlerine ek olarak ücretsiz eğitimler verilmesi önde gelmektedir. Bu şekilde binlerce kişi uygulamalı girişimcilik eğitimi almış bulunmaktadır. KOSGEB bu eğitimleri çeşitli bakanlıklar, üniversiteler, sivil toplum kuruluşlarıyla işbirliği içinde yapmaktadır. Birçok kurum ya da sivil toplum kuruluşu (İşadamları dernekleri, gençlik, eğitim vs vakıflar vb kuruluşlar) belli şartları sağladığında ve belli sayıda girişimci adayı olduğunda bu eğitimleri ücretsiz olarak alabilmektedirler.

Verilen eğitimlerde daha çok girişimcilik eğilimini etkileyen kişilik özellikleri üzerinde durulmaktadır. Verilen mevzuat bilgisi, teknik detayların yanında motivasyon eğitimi de verilmektedir. Ancak bu eğitimlerde, katılımcların daha iyi tanınması, özelliklerinin belirlenmesi ve herkese en uygun olan girişim yol haritasının çizilmesi gerekmektedir. 
Son yıllarda psikolojik sermayenin girişimcilikteki öneminin daha çok farkına varılmaya başlanmıştır. Bireylerin girişimci olma kapasitelerinin önemli bir boyutunu oluşturan psikolojik sermayelerinin ölçülmesi ve bireylerce bu konuda farkındalık oluşturulması faydalı olacaktır. Uygulamalı girişimcilik eğitimi alan bireylerin girişimci olması birçok farklı faktöre bağlı bulunmaktadır. Sadece bireysel değil aynı zamanda yasal, sosyal, ekonomik faktörlere de dikkat etmek gerekmektedir. Ülke ekonomisinin dönemsel durumu da girişimcilik oranlarını etkilemektedir. Tüm bu faktörlerin birleşiminden oluşan girişimcilik kültürü içerisinde psikolojik sermaye önemli bir yer tutmaktadır.

Bu nedenle bu çalışmada psikolojik sermaye bakış açısı kullanılmıştır. Bu çalışmanın amacı KOSGEB'in koordine ettiği bu eğitimlerin daha fazla girişimci çıkarması yönünde oluşabilecek muhtemel engellerden biri olan kişilerin psikolojik sermaye seviyelerinin araştırılması ve bu durumun girişimciliği nasıl etkilediğinin ortaya konulmasıdır. Bu sayede psikolojik sermaye değişkenin alt boyutları ile girişimcilerin bir girişim yapma yönünde psikolojik cesaretleri arasındaki ilişki anlaşılabilecektir. Psikolojik sermayesi güçlü bireyler girişim sırasında yaşayabilecekleri girişimcilik stresi ile daha kolay baş edebilme gücüne sahip olacaklardır. Dolayısıyla, bu çalışmanın kapsamına, KOSGEB tarafından düzenlenen ve sadece girişimci olma niyeti ile kursa katılanlar dahil edilmiştir. Son yıllarda devletin de girişimciliğe önem vermesinin bir sonucu olarak, uygulamalı girişimcilik eğitimleri birçok yerde ve ücretsiz olarak alınabilmektedir. Bilindiği üzere girişimcilik sertifikası üniversitelerde "girişimcilik" dersi alan öğrencilere de verilmektedir. Fakat üniversitedeki ders kanalı ile sertifika alanların tamamı bir girişim yapma düşüncesi ile dersi almadığı için araştırma kapsamına dahil edilmemiştir.

\section{Girişimcilik Eğitimi}

Literatüre bakıldığında, girişimcilik eğitimi ile girişimcilik eğilimi arasındaki ilişkilere dair birçok araştırma bulunmaktadır (Örneğin, Fayolle ve Gailly, 2015; Elert vd., 2015; Walter ve Block, 2016; Nabi vd., 2017). Bu konuda uluslararası ve ulusal düzeyde birçok çalışma bulunmaktadır. Ülkemizde bu konuda yapılan bazı çalışmaları gözden geçirmek faydalı ola- 
caktır. Bozkurt vd. (2012) tarafından yapılan çalışmada ülkemizdeki girişimcilik eğilimlerinin ortaya çıkarılmasında ve girişimci oranının arttırılmasında girişimcilik eğitiminin son derece etkili olduğu sonucuna varılmıştır. Bozkurt ve Erdurur (2013), girişimcilikte kişilik özelliklerinin girişimcilik eğilimini doğrudan etkilemesinin yanında girişimcilik eğitiminin de dolaylı olarak etkili olduğunu söylemiştir. Uluköy vd. (2013) yaptıkları araştırma sonucunda girişimcilik eğitimi alan bireylerin girişimcilik eğilimlerinin arttığını bulmuşlardır. Pazarcık ve Aydın (2015) yaptıkları çalışmada girişimcilik eğitiminin öğrencilerin girişimcilik eğilimlerini pozitif şekilde etkilediği sonucuna varmışlardır. Büyükyılmaz vd. (2015, s.110), girişimcilik eğitiminin üniversitelerde verilmesinin, potansiyel girişimcileri ortaya çıarma ve geliştirme açısından önemli olduğunu savunmaktadır. Özdemir (2016) üniversite müfredatları bağlamında, ülkemizdeki üniversitelerde girişimcilik eğitiminin giderek daha çok önem kazandığını ifade etmiştir. Çolakoğlu ve Çolakoğlu (2016) yaptıkları çalışmada, girişimcilik eğitiminin bireylerin öz yeterlilik algısın geliştirerek girişimcilik potansiyellerini değerlendirmeye pozitif etkide bulunduğunu bulmuşlardır. Güner ve Korkmaz (2016), uygulamalı girişimcilik eğitimlerinin etkinliğini, bu eğitimi aldığı halde iş kurmayan/kuramayan katılımcıları analiz ederek, farklı ama gerçekçi bir şekilde ele almışlardır. Alpaslan vd. (2017) girişimcilik eğitim programlarının daha etkin hale getirilmesi için önerilerde bulunmuşlardır. Özdemir vd. (2018) girişimcilik eğitiminin girişimcilikte etkili olan kişilik özelliklerini ortaya çıararak girişimcilik eğilimini pozitif etkilediği sonucuna varmışlardır. Uygun vd. (2018) girişimcilik eğitiminin her şeyden önce katılımcıların motivasyonunu artırmak suretiyle girişimciliği artırdığını ifade etmişlerdir. Aksoy vd. (2019) benzer şekilde konuya motivasyon açısından yaklaşmışlardır. Namal vd. (2018) KOSGEB eğitimleri örneğinde girişimcilik eğitiminin kendinden beklenen fonksiyonları yerine getiremediği eleştirisini yapmaktadırlar.

Görüldüğü üzere girişimcilik eğitimi birçok araştırmanın da ortaya ç1kardığı gibi, girişimcilik faaliyetlerini doğrudan etkileyen ve eğitime katılan bireyleri etkileyen bir süreçtir. Yapılan çalışmalar, genelde girişimcilik eğitimini belli bir içerik olarak ele alsalar bile, verilen eğitimin psikolojik etkileri ve uzun vadede ortaya çıabilecek olan olumlu sonuçları üzerinde yeterince durulmamıştır. 


\section{Psikolojik Sermaye}

Psikolojik sermaye kavramı günümüz çalışma hayatının gelişimi için insan kaynaklarının üstün yönleri ve psikolojik kapasiteleri üzerinde yapılan çalışmalar sonucunda ortaya çıkmış pozitif yönelimli bir kavramdır (Luthans ve Youssef-Morgan, 2017; Samir vd., 2019). Psikolojik sermayenin günümüzde geldiği noktayı ve anlamının anlaşılabilmesi için tarihsel süreç içinde geçirdiği evrimi gözden geçirmek gerekmektedir. Ekonomik sermaye, insani sermaye ve sosyal sermaye kavramlarının sonrasında gelişen psikolojik sermaye kavramı, dördüncü ve son boyut olarak insanın sahip olduğu psikolojik güçleri ifade etmektedir. Psikolojik sermaye, sürecin son halkası olması dolayısıyla bütünleyici bir etkiye sahiptir ve dolayısıyla, insani ve sosyal sermayenin tek başlarına yapacağı etkiden daha büyük bir potansiyele sahiptir (Luthans vd., 2007a). Kişisel gelişime ve performansa bireysel olarak destek olan Psikolojik Sermayenin; bu unsurların gelişmesiyle beşeri ve sosyal sermayenin gücünü, verimliliğini, rekabet avantajını ve yatırım getirisini pozitif yönde etkilemesi bakımından örgütsel yapılanmanın olduğu kamuda, özel sektörde ve sivil toplum kuruluşlarında yönetilmesi gereken bir güç olduğu belirtilmektedir (Luthans ve Youssef, 2007). Psikolojik sermaye bireylerin şimdiki zamanda sahip olduğu ve gelecek zamanda gelişim sağlayacağı özellikler bütünü olarak temel bir sermaye bütününü ifade etmekte ve psikolojik sermayenin dört alt boyutu bulunmaktadır. Bunlar; bireyin işine yönelik gerekli çabayı göstereceğine ilişkin kendine güvenmesi "öz yeterlilik", şimdi ve gelecekte başarılı olmaya ilişkin olumlu yaklaşımı "iyimserlik", amaçların başarılmasına yönelik beklentisi "umut" ve zorluklar karşısında sağlam duruşunu gösteren "dayanıklılık" olarak tanımlanmaktadır (Luthans vd., 2007b). Bununla birlikte psikolojik sermayenin bu boyutlardan farklı olarak bütüncül bir yapıya sahip olduğu özellikle belirtilmelidir.

\section{Psikolojik Sermaye Boyutlarn}

Literatürde, psikolojik sermaye kavramını ve sürecini oluşturan dört boyuttan söz edilmektedir. Bu boyutlar hem kendi aralarında hem de psiko- 
lojik sermaye kavramıyla etkileşim içerisinde bulunmaktadır. Bu boyutların anlaşılması hem psikolojik sermaye kavramının daha iyi anlaşılmasını sağlayacaktır hem de bu şekilde psikolojik sermayenin bütünsel olarak ve boyutlar düzeyinde girişimcilikteki rolü daha iyi anlaşılacaktır.

Öz yeterlilik: Öz yeterlilik kavramı, psikolojik sermayenin önemli bir alt bileşenidir. Kısaca tanımlamak gerekirse, öz yeterlilik, bireyin belli durumlarda belirli bir görevi başarıyla yerine getirmek için gereksinim duyduğu güdü ve davranışı göstermesi konusunda kendisine duyduğu güven ve kendisi hakkındaki inancidır (Stajkovic ve Luthans, 1998a, 1998b; Luthans ve Youssef, 2004; Youssef- Morgan ve Luthans, 2015). Bireylerin özgüven konusundaki inanç ve tutumlar inanışları aracılı̆̆ıyla bilişsel, motivasyonel, duygusal ve karar verme süreçleri ile ifade edilen dört büyük süreç aracılığg ile bireylerin iç dünyalarındaki işleyiş düzenlemektedir. Kişilerin kendileri hakkındaki bu inançları insanların kendini güçlendiren ve zayıflatan şekillerde kötümser ve iyimser şekilde düşünmelerine yol açmakta ve dolayısıyla girişimcilik kararlarını etkilemektedir. Bireylerin kendilerini girişimcilik yapma konusunda yeterli görmeleri, bu düşüncelerini gerçekleştirmek için harekete geçmelerini kolaylaştırmaktadır. Bu durum insanların çabalarıyla ilgili sonuç beklentilerini de biçimlendirmektedir.

Umut: Umut duygusu insan hayatındaki en önemli duygulardan birisidir ve umut seviyesi yüksek olan bireyler, daha fazla hedefe odaklıdır ve bu hedefleri gerçekleştirmek için alternatif yollar ararlar (Snyder, vd. 1991, s.287; Luthans vd., 2007). Umut kavramının bireyin amacı gerçekleştirme isteğini ifade eden birinci boyutu ile bireyin arzu ettiği bir sonuca ulaşmasını sağlayacak davranışları gerçekleştirmesi için lazım olan kapasiteye sahip olduğu kanaati olarak ifade edilen öz-yeterlilik arasındaki temel fark; umut kavramının bireyin içinden gelen harekete geçme isteği ile özyeterlilik kavramının bireydeki harekete geçebilme kapasitesi ve yeterliliği ile ilişkili olmasıdır (Lopez, 2013). Başka bir deyişle, umut kavramı bireylerin sahip oldukları öz yeterliliğin harekete geçirilmesi için bir motivasyon faktörü olarak düşünülebilir. 
İyimserlik: İyimserlik umut kavramına oldukça benzemektedir ve bireysel pozitif çıtı beklentisi olarak ifade edilebilir. Yapılan araştırmalarda, iyimserliği yüksek olan bireylerin zorlu durumlarla başa çıkmalarının daha kolay olduğu ve belirledikleri hedefe ulaşmak için kendilerini daha çok motive ettikleri görülmüştür (Seligman, 1998, s.2; Luthans vd., 2007). Kişilerin olayları ve tutumları açılama şekilleri, kendi bireysel yorumlarından ibaret olduğundan, her zaman objektif ve esnek olmamaktadır.

Dayanıklılık: Dayanıklı bireyler zorluklarla karşılaştıkları zaman bunu yaşamın bir parçası olarak görürler ve bundan kendilerine olumlu bir anlam çıkarırlar (Masten ve Reed, 2002). Dayanıklılık, negatif olaylarla karşı karşıya kalmaktadır, daha yüksek düzeyde dayanıklılığa sahip bireyler, olumsuz durumları ve gerilemeyi sorunsuz şekilde halledebilirler (Tugade vd., 2004).

Yukarıda ifade edilen dört psikolojik sermaye boyutu kavramsal olarak birbirinden bağımsızdır (Luthans vd., 2007) ve ampirik olarak geçerlidir (Bryant ve Cvengros, 2004).

\section{Psikolojik Sermaye ve Girişimcilik İlişkisi}

Yapılan birçok araştırma, girişimciliğin ekonomik büyüme ve gelişmenin itici gücünü oluşturduğu konusunda hemfikirdir. Özellikle son yüzyılda, belirsizliğin arttığı ortamlarda yeni girişimlerde bulunmak önemli bir strateji olarak karşımıza çıkmaktadır. Girişimcilerin yeni durumlara ve ortamlara uyum sağlaması ancak var olan bazı girişimcilik özelliklerinin kullanılmasıyla mümkün olabilir. Ortaya atılan birçok çözüm yolu arasında içsel kaynaklarla dışsal kaynakları birleştirmek amacıyla psikolojik sermayenin girişimcilik eğilimini tetiklemesi de bulunmaktadır. Psikolojik sermaye diğer sermaye türlerinden farklı olarak girişimcilik eğilimini dolaylı ve örtük bir şekilde etkilemektedir. Psikolojik sermaye, kişinin kendi bakış açısına veya özgüven duygusuna yansımaktadır (Goldsmith vd., 1997). Böylece, psikolojik sermayeye, bir kişinin bir kuruma üretken bir şekilde getirdiği finansal, beşeri ve/veya sosyal sermayeyi başarılı bir şekilde kullanma kabiliyetinin bir algısı veya görüşü olarak bakılabilir. Ayrıca, psikolojik sermayenin şekil verilebilir olan doğası, girişimcilere kendi psikolojik sermayelerini ve çalışanlarının güçlerini geliştirme fırsatı 
sunmaktadır. Girişimcilik başarısının sadece finansal kazanımları değil aynı zamanda memnuniyet, şükran duygusu ve hazırlık gibi psikolojik başarı ölçütlerini içerdiği vurgulanmaktadır (Sisodia vd., 2007; Tang vd., 2010).

Hmieleski ve Carr (2008) girişimci Psikolojik Sermaye ve yeni girişim performansı konusunda yapmış oldukları, çalışmada, girişimcilerin psikolojik sermayesi ile yeni girişimlerinin performansı arasındaki ilişkiyi araştırmışlardır. Bu çalışma sonucunda, girişimcilerin psikolojik sermayesinin, finansal girişim, beşeri sermaye ve sosyal sermaye boyutlarının ötesinde, yeni girişim performansını etkilediği ortaya konmuştur. Psikolojik sermaye birçok yazara göre yaratıcllık üzerinden girişimciliği etkilemektedir (Avey vd., 2012) bu bağlamda psikolojik sermayenin bireylerin yaratıcllı̆̆ını ciddi şekilde yükseltme potansiyeline sahip olduğu düşünülmektedir (Sweetman vd., 2011). Jensen (2012), psikolojik sermaye ve girişimsel stres konusundaki çalışmasında, psikolojik sermayenin (öz-yeterlilik, umut, iyimserlik ve esneklikten oluşan) temel yapısının, bireylerin stresi nasıl algıladıklarının anlaşılmasına yardımcı olduğunu söylerken, psikolojik sermayenin girişimciliği dolaylı olarak etkilediği sonucuna varmışlardır. Frese ve Gielnik (2014), (genel) öz yeterlik ve başarı ihtiyacı gibi kişilik boyutlarının ve girişimcilik oryantasyonunun girişimcilikle (iş yaratma ve iş başarısı) yakından ilişkili olduğunu göstermiştir. Bockorny (2015) psikolojik sermayenin girişimciliği özellikle cesaret alt bileşenine etki ederek artırdığı sonucuna ulaşmıştır. Günümüz dünyasında girişimciler başarıyı yalnızca finansal olarak değil psikolojik olarak da algılarlar (Gorgievski vd., 2011). Öğe ve Kaplan (2016) psikolojik sermaye ve girişimcilik eğilimi ilişkisini sadece kavramsal düzeyde ele almışlardır. Özdemir ve Özgüner (2016) ise psikolojik sermayenin girişimcilik eğilimini olumlu yönde etkilediğini ifade etmişlerdir. Görüldüğü üzere, literatürde psikolojik sermaye ile girişimcilik eğilimi arasında genelde pozitif bir ilişki olduğu vurgulanmaktadır. Psikolojik sermaye kavramı dolaylı olarak da olsa girişimcilik eğilimini etkilemektedir.

\section{Yöntem}

Bilindiği üzere KOSGEB tarafında her yıl çok sayıda ücretsiz uygulamalı girişimcilik eğitimleri verilmektedir. Burada eğitim alan bireylerin daha 
önce de yapılan çalışmalarda görüldügüü üzere yaklaşık \%10'u bir işletme kurarak gerçek manada bir girişimci olmaktadır (Uluköy vd.,2013). Eğitime katılan kursiyerlerin psikolojik sermaye seviyelerinin girişimci olmaya etkisini araştıran bu çalışma sadece KOSGEB tarafından girişimcilik eğitimi sertifikası alan katılımcılar üzerinde yapılarak psikolojik sermayenin etkisini görmeyi amaçlamaktadır. Araştırmanın evrenini Kütahya'da KOSGEB eğitimi almış sertifika almaya hak kazanmış katılımcılar oluşturmaktadır. Bu doğrultuda daha önce girişimcilik sertifikası alan 210 katılımcı ile anket gerçekleştirilmiştir. Psikolojik sermaye ile girişimcilik alg1ları arasındaki ilişkiyi test etmek amacıyla korelasyon analizi yapılmıştır. Bunun yanında iki değişken arasında etkiyi görebilmek için ise regresyon analizi yapılmış $\mathrm{R}^{2}$ hesaplanmıştır.

Araştırmada psikolojik sermayeyi ölçmek için Luthans vd. (2007) tarafından geliştirilen ölçekten faydalanılmıştır. Bu ölçek 4 boyut ve 24 sorudan oluşmaktadır. Her bir boyutta 6 soru bulunmaktadır. Bu boyutlar; öz yeterlilik, iyimserlik, umut ve dayanıklılıktır. Araştırmada, ölçeğin Türkçe versiyonu Çetin ve Basım (2012) tarafından uyarlanan güvenilirlik ve geçerliliği kabul edilen çalışmadan alınmıştır. Girişimcilik potansiyelini belirlemeye yönelik sorular ise Ören ve Biçkes (2011) tarafından tercüme edilen ve bir girişimcilik merkezi olan Central of Rural Entreprenuership tarafından hazırlanan önermelerden yararlanılarak oluşturulmuştur. Çalışmanın güvenilirliği için yapılan analiz neticesinde Cronbach Alpha değeri 0,83 olarak bulunmuştur. Güvenilirlik katsayısının 0,70'den daha yüksek oluşu psikolojik sermaye ve girişimcilik potansiyeli ölçeklerinin oldukça güvenilir olarak nitelemek için yeterli bir değerdir.

\section{Hipotezler}

Araştırmanın hipotezleri aşağıda sunulmaktadır;

- H1: Psikolojik sermaye alt boyutu öz yeterlilik, girişimcilik eğilimini pozitif olarak etkiler.

- H2: Psikolojik sermaye alt boyutu iyimserlik, girişimcilik eğilimini pozitif olarak etkiler.

- H3: Psikolojik sermaye alt boyutu umut, girişimcilik eğilimini pozitif olarak etkiler. 
- H4: Psikolojik sermaye alt boyutu dayanıklılık, girişimcilik eğilimini pozitif olarak etkiler.

\section{Bulgular ve Tartışma}

Öncelikle araştırmadaki demografik faktörlerden bahsetmekte yarar bulunmaktadır. Araştırma verilerinin analiz edilmesi sonucunda katılımc1ların yaş ortalamasının 28,3 olduğu ve 18 ile 45 yaş arasında değiştiği saptanmıştır. Katılımcıların \% 43,8' i (92) erkek ve \%56,2'Sİ (118) kadınlardan oluşmaktadır. \% 20,1'i ortaöğretim , \%14,7'u ön lisans, \%55'i lisans, $\% 10,2$ 'si lisansüstü eğitimi görmüştür. Katılımcıların \%60,8'i evli iken \%39,2'si bekârdır.

Görüldüğü üzere girişimci adayları oldukça genç, kariyerlerinin başında bulunmakta; giriş̧imci adayları arasında kadınların çoğunluğu oluşturması dikkat çekmektedir. Katılımcıların ve potansiyel girişimci adaylarının çoğunluğu lisans derecesine sahip ve evli olan bireylerden oluşmaktadır. Bu durum, üniversite mezunlarının iş gücü piyasasındaki daralmadan etkilenerek kendi işlerini kurmak istedikleri şeklinde de yorumlanabilir.

Tablo 1: Psikolojik Sermaye Düzeyleri İle Girişimcilik Niyeti Arasında İlişki Korelasyon Tablosu

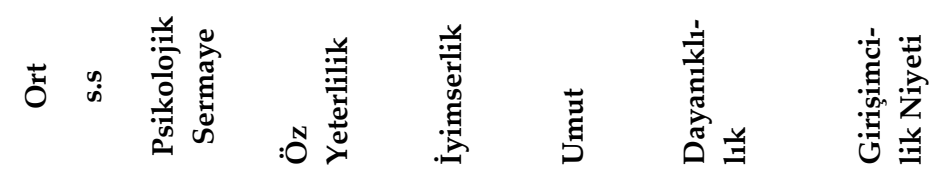

Psikolojik $3,18,54 \quad 1$

Sermaye

\begin{tabular}{|c|c|c|c|c|c|c|c|}
\hline Öz Yeterlilik & $3,44,51$ & - & 1 & & & & \\
\hline İyimserlik & $3,52,47$ & - & - & 1 & & & \\
\hline Umut & $3,82,57$ & - & - & - & 1 & & \\
\hline Dayanıklılık & $3,63,58$ & - & - & - & - & 1 & \\
\hline $\begin{array}{l}\text { Girişimcilik } \\
\text { Niyeti }\end{array}$ & $3,51,78$ & ,731 &, $513^{* *}$ &, $328^{* *}$ &, $545^{* *}$ &, $611^{* *}$ & 1 \\
\hline
\end{tabular}


Elde edilen Pearson Korelasyon Katsayılarından (r) hareketle, psikolojik sermaye ve alt boyutları ile girişimcilik niyet arasında farklı düzeylerde olmakla birlikte pozitif yönde bir ilişki olduğu tespit edilmiştir $(\mathrm{p}<0.01)$. Değişkenler arasındaki korelasyon katsayısının 0,30-0,64 arasında olması durumunda orta; 0,65-0,84 arasinda olması durumunda kuvvetli; 0,85-1 arasında olması durumunda ise ilişkinin seviyesi çok kuvvetli olarak değerlendirilmektedir (Ural ve Kılıç, 2006:248). Buradan hareketle girişimcilik niyeti ile psikolojik sermaye arasında pozitif yönlü kuvvetli bir ilişki olduğunu söylemek mümkündür $(\mathrm{r}=0,73)$. Psikolojik sermayenin öz yeterlilik $(\mathrm{r}=0,513)$, iyimserlik $(\mathrm{r}=0,328)$, umut $(\mathrm{r}=0,545)$ dayanıklılık boyutu arasında ise orta düzeyde pozitif bir ilişki tespit edilmiştir $(\mathrm{r}=0,611)$.

Tablo 2: Psikolojik Sermaye Düzeylerinin Girişimcilik Niyetine Etkisi

\begin{tabular}{|c|c|c|c|c|c|}
\hline \multirow[t]{3}{*}{ Model } & \multicolumn{2}{|c|}{$\mathrm{R}^{2}=0,667$} & \multicolumn{3}{|c|}{ Ayarlanmış $R^{2}=0,520$} \\
\hline & \multicolumn{2}{|c|}{$\mathrm{F}=46,300$} & \multicolumn{3}{|c|}{$\mathrm{P}$ değeri $=, 000$} \\
\hline & B & Std. Hata & Beta & $\mathrm{t}$ & P. Değeri \\
\hline Sabit &,- 554 & ,331 & & $-1,674$ & ,097 \\
\hline Öz Yeterlilik & ,324 & 118 & 299 & 2,743 & ,007 \\
\hline İyimserlik & ,172 & 113 & 147 & 1,522 & 013 \\
\hline Umut & ,286 & 119 & ,253 & 2,397 & ,018 \\
\hline Dayanıklılık & 021 & 0,64 & 0,26 & ,334 & ,739 \\
\hline
\end{tabular}

Bağımlı Değişken: Girişimcilik Niyeti

Tablo 2'ye göre psikolojik sermayenin ve bunu oluşturan alt boyutlarının girişimcilik niyeti üzerinde anlamlı bir etkiye sahip olduğu belirlenmiştir ( $p=0,000)$. $R^{2}$ değeri 0,667 olarak bulunmuştur. Bağımsız değişkenlerden Bağımsız değişkenlerden öz yeterlilik için $\beta=0,324$, iyimserlik için $\beta=.172, p=.001$, umut için $\beta=.286$ değerlerine ulaşılmıştır. Bu sonuçlara göre psikolojik sermaye seviyelerinin girişimcilik niyetine pozitif yönde etkilediği ve bu etkinin istatistiki olarak güçlü anlamlılığa sahip olduğu görülmektedir. 


\section{Sonuç ve Değerlendirme}

Girişimciliğin gelişmesi açısından girişimciliği etkileyen faktörlerin anlaşılması hem eğitim verenler hem de yeni girişimlerin başlaması açısından oldukça önemlidir. Bu araştırmada KOSGEB girişimcilik eğitimi alan kursiyerlerin öz yeterlilik, iyimserlik, umut ve dayanıklılık boyutlarından oluşan psikolojik sermayenin girişimcilik niyetine etkisi araştırılmıştır. Araştırma bulgularına göre, psikolojik sermaye ve alt boyutları ile girişimcilik niyeti arasında anlamlı ilişkiler tespit edilmiştir. Öz yeterlilik ve umudun katılımcıların girişimci olma yönündeki niyetlerini etkilediği görülmektedir. Bu durum, literatürdeki diğer araştırmaların sonuçlarıyla uyumlu görünmektedir (Boyd ve Vozikis, 1994; Basım ve Şeşen, 2012; Erkmen ve Esen, 2012; Canbaz ve Cankır 2013; Polatçı, 2014; Özdemir ve Özgüner, 2016).

Bu araştırma kapsamında ele alınan dört hipotezden 2 tanesi kabul edilirken 2 tanesi reddedilmiştir. Kabul edilen hipotezlerimiz şunlardır;

- H1: Psikolojik sermaye alt boyutu öz yeterlilik, girişimcilik eğilimini pozitif olarak etkiler.

- H3: Psikolojik sermaye alt boyutu umut, girişimcilik eğilimini pozitif olarak etkiler.

Boyd ve Vozikis (1994) tarafından yapılan araştırmada öz yeterlilikleri yüksek olan bireylerin girişimcilik eğilimlerinin daha yüksek olduğu tespit edilmiştir. Aynı şekilde Basım ve Şeşen (2012) tarafından yapılan çalışmada ise girişimcilik ile öz yeterlilik arasında pozitif ilişki bulmuştur. Kabul edilen $\mathrm{H} 3$ hipotezi ile de literatürde benzer sonuçlara rastlamak mümkündür. Erkmen ve Esen (2012)'e göre umutlu bireyler zorlukların üstesinden gelme konusunda daha isteklidirler demiştir. Canbaz ve Cankır (2013) ise umutları, hayalleri olan bireylerin değişime ve performansa fırsat verecek iş yapma potansiyeline sahip olacaklarını ifade edilmiştir. Benzer bir şekilde Polatçı (2014)'de hedef koymanın ve bu hedefe ilerlemeleri noktasında "umut" alt boyutunun önem taşıdığını ifade etmiştir. ChangHyun (2017) pozitif psikolojik sermayeyi içeren alt faktörlerin, yani umut, dayanıklılık ve öz yeterliliğin başlangıç niyetini olumlu yönde etkilediğini göstermektedir. Bununla birlikte, bir başka alt faktör olan iyimserlik, başlangıç niyetinde önemli bir etkiye sahip değildir. 
Literatürde psikolojik sermaye ile yapılmış farklı çalışmalara bakıldığında yine umut ve öz yeterliliğin farklı değişkenlerde etkisinin olduğu çalışmalara rastlamak mümkündür. Harter vd., (2002); Cogner ve Kanungo, (1988); yapmış oldukları çalışmalarda umut alt boyutunun çalışan memnuniyetini dolaylı olarak performansı arttırdığını ifade etmişlerdir. Rathi ve Rastogi, (2009) mesleki öz yeterlilik ile örgütsel bağlllık arasında pozitif ilişki olduğundan bahsetmiştir. Schyns, (2004); Schyns ve von Collani, (2002); Sinha vd., (2002) yapmış oldukları çalışmalarda öz yeterliliğin; iş tatmini, örgütsel bağlılık ve örgütsel değişime hazırlıklı olma gibi örgütsel tutum sonuçları ile pozitif ilişkili olduğu sonucuna varmışlardır. Chaudhary, Rangnekar and Barua, (2012); Kumar \& Sia, (2013) öz yeterlilik ile işe adanmışlık arasından pozitif ilişki olduğunu tespitini yapmışlardır. Görüldüğü gibi farklı konular üzerinde yapılan çalışmalarda da umut ve öz yeterliliğin etkisi olduğu sonucuna varılmaktadır. Bu durum yapmış olduğumuz çalışma ile benzerlik göstermektedir.

Bu çalışmayı diğer çalışmalardan ayıran en önemli özellik, KOSGEB Girişimcilik kursuna bir girişimci olma niyeti ile başlayıp sertifika alanlar üzerinde yapılmış olmasıdır. Literatür tarandığında üniversite öğrencileri üzerinde ve hali hazırda sektörde faaliyet gösteren firmalarda çalışanlar üzerinde yapılmış çalışmalara rastlamak mümkündür (Örneğin Önay vd., 2017; Özdemir vd., 2018). Üniversitelerde verilen girişimcilik eğitimi bölümden bölüme değişiklik gösterirken bazı bölümlerde zorunlu ders olarak okutulmaktadır. Bu durum ise girişimci olma niyeti olmayan bireyin de örneklem grubuna dahil olmasına sebep olmaktadır. Aynı şekilde hali hazırda faaliyet gösteren işletmelerde yapılan çalışmalarda ise psikolojik sermaye seviyelerinin yani girişimcilik sırasında ortaya çıkan stresin yönetilme durumunun daha önce başarılmış ve neticelenmiş olduğu anlaşılmaktadır. Oysa ki psikolojik sermaye ilk defa girişimci olacak bireylerin girişimci olma niyetine ilk etkilerini görmemiz açısından önem teşkil etmektedir.

Çalışmanın hem akademik anlamda hem de uygulamada bazı katkılarının olması beklenmektedir. Öncelikle mevcut sistemdeki girişimcilik eğitimlerinde, adayların ve katılımcıların kişilik özellikleri, yetkinlikleri ve özellikle psikolojik sermayeleri yeterinde dikkate alınmadan eğitim içerikleri oluşturulmaktadır. Standart girişimcilik özelliklerinin yerine ki- 
şiye özel ve farklı altyapı ve hayallere sahip bireylere yönelik olarak farklılaştırılmış ve uygulamaya dönük, öğrenci-merkezli anlayışla eğitimler verilmelidir. Verilen eğitimlerin ne kadar amaca hizmet ettiği, belli anketlerle ölçülmeye çalışılsa da asıl araştırılması gereken konu, bu eğitimlerin hangi oranda girişimciliğe katkı yaptığıdır. Bununla ilgili sınırlı sayıda akademik çalışma mevcuttur ve bazı çalışmalar girişimciye dönüşemeyen katılımcların özelliklerini ve başarısızlığın sebeplerini irdelemektedir (Örneğin Güner ve Korkmaz, 2016). Bu tür gerçekçi ve çözüm-odaklı çalışmaların artması gerekmektedir. Girişimcilik eğitimlerinin planlanmasında ve eğitimin verilmesi sürecinde katılımclların farklı özellikleri dikkate alınmalıdır.

Her ne kadar bu çalışmayla, üzerinde yeterince durulmayan ve girişimcilikte çok önemli role sahip olan psikolojik sermaye ve girişimciliğe etkisi üzerinde durulmuş olsa da, bu çalışmada da bazı kısıtlar bulunmaktadır. Metodolojik anlamda bazı kisitlardan bahsetmek gerekirse, uygulanan anketleri dolduran katılımcıların samimi bir şekilde doğru bilgiler verdikleri varsayılmaktadır. Bu durum kantitatif çalışmaların genel kısıtlarından birisidir. Anket uygulaması yanında nitel ve derinliğine veri toplamayı amaçlayan başka yöntemler de düşünülebilirdi. Uygulamaya belli bir çevrede girişimcilik eğitimine katılan sınırlı sayıda örneklemle bu çalışma yapılmıştır. Bu çalışmanın ayrıca eğitim öncesi ve eğitim sonrası (pre-test ve post-test) karşılaştırmalara imkan verecek şekilde tekrarlanması da faydalı olabilir. Bu çalışma Kütahya iline bağlı KOSGEB kurslarına uygulanmıştır. Bu açıdan sınırlı bir bölge ve bölge insanına ulaşılmıştır. Bilindiği üzere farklı bölge insanlarının girişimciliğe bakış açıları farklılık gösterebilmektedir. Gelecek çalışmalar için farklı illerdeki KOSGEB kurslarına katılanlara da bu çalışma uygulanabilir. Bunun yanında yine KOSGEB aracılığı ile işletme açanlara bu çalışma uygulanarak psikolojik sermaye seviyeleri ile işyeri açma ilişkisi ortaya koyulmaya çalışılabilir. 


\title{
EXTENDED ABSTRACT
}

\section{The Effect of Psychological Capital on Entrepre- neurial Tendency: A Research on Trainees Attended to KOSGEB Entrepreneurship Education}

\author{
Vasfi Kahya \\ Dumlupinar University
}

The phenomenon of entrepreneurship is of vital importance for the economic development in our country. Entrepreneurship education, which is one of the important issues in the field of entrepreneurship, has been on the agenda for many years and has been used in our country, but it has become widespread especially since the 2000s. Many factors contributed to the development of entrepreneurship education in this process. These factors include the contributions of NGOs, governments and related organizations, in particular universities, ministries and KOSGEB. Increasing awareness of non-governmental organizations on entrepreneurship has been particularly effective in recent years. In addition, the entrepreneurship courses and entrepreneurship trainings offered at universities, as well as the practical entrepreneurship training provided by many private and public institutions, led to an increase in entrepreneurship initiatives.

In this context, with the increase in the number of entrepreneurial universities, entrepreneurship education has also become widespread in parallel and the number of entrepreneurs has continued to increase in recent years (Özdemir, 2017, p.3). In particular, it is worth mentioning the practical entrepreneurship trainings conducted under the coordination of KOSGEB directly assigned to this task. One of KOSGEB's important tasks is to support citizens in different ways in the process of engaging in small and medium level entrepreneurs. In addition to grants, projects and consultancy services provided to existing entrepreneurs, grants and consultancy services provided to future entrepreneurs are provided free of charge. Thousands of people have received practical entrepreneurship 
training courses. Many institutions or non-governmental organizations (associations of businessmen, youth, education etc. foundations, etc.) can receive these trainings free of charge when they meet certain conditions and have a certain number of entrepreneur candidates.

In recent years, the importance of psychological capital in entrepreneurship has started to be realized more. It will be useful to measure the psychological capital of individuals, which constitutes an important dimension of their capacity to become entrepreneurs, and to raise awareness of this issue by individuals. The number of new entrepreneurs depends on many different factors. Not only the individual, but also legal, social, economic factors should be paid attention to. The current situation of the national economy also affects the entrepreneurship rates. Psychological capital occupies an important place in the culture of entrepreneurship which is composed of all these factors. Therefore, psychological capital perspective was used in this study. The aim of this study is to investigate the psychological capital levels of people who are one of the possible obstacles that may lead to more entrepreneurship of these trainings coordinated by KOSGEB and to show how this affects entrepreneurship. In this way, the relationship between the sub-dimensions of the psychological capital variable and the psychological courage of entrepreneurs to make an attempt will be understood. Individuals with strong psychological capital will be able to cope more easily with the entrepreneurial stress they may experience during the enterprise. Therefore, the scope of this study included the participants of the entrepreneurship training course organized by KOSGEB. As a result of the state's emphasis on entrepreneurship in recent years, applied entrepreneurship trainings can be taken in many places and free of charge. As it is known, entrepreneurship certificate is also given to students who take "entrepreneurship" course in universities. However, not all of the students who received certificates through the course channel at the university were not included in the research since they did not take the course with the intention of making an initiative.

As seen in the previous studies, approximately $10 \%$ of the individuals who are educated here become entrepreneurs by establishing a business. This study investigating the effect of psychological capital levels of trainees participating in training on entrepreneurship aims to see the effect of 
psychological capital only on participants who have received entrepreneurship training certificate by KOSGEB. The population of the research consists of participants who have received KOSGEB training certificate in Kütahya. In this respect, a questionnaire was conducted with 210 participants who had previously received entrepreneurship certificate. Correlation analysis was performed to test the relationship between psychological capital and entrepreneurship perceptions. In addition, regression analysis is made to see the effect between the two variables.

In order to measure psychological capital, the scale was adopted from Luthans et al. (2007). This scale consists of 4 dimensions and 24 questions. There are 6 questions in each dimension. These dimensions are; self-efficacy, optimism, hope and resilience. In the study, the Turkish version of the scale was obtained from the study of Cetin and Basim (2012). Questions to determine the potential of entrepreneurship were developed by using the propositions translated by Ören and Biçkes (2011) and prepared by Central Entrepreneurship. As a result of the analysis conducted for the reliability of the study, Cronbach Alpha value was found to be 0.83 . The reliability coefficient higher than 0.70 is sufficient to qualify the psychological capital and entrepreneurial potential scales as highly reliable. The concept of psychological capital is a positive-oriented concept emerged as a result of studies on the superior aspects and psychological capacities of human resources for the development of today's working life. In this study, the effect of this variable on entrepreneurship was determined by evaluating the psychological capital levels of the trainees participating in KOSGEB Entrepreneurship training.

Understanding the factors that affect entrepreneurship in terms of the development of entrepreneurship is very important both for educators and for the initiation of new initiatives. In this study, the effect of psychological capital, which is composed of self-efficacy, optimism, hope and endurance dimensions of trainees receiving KOSGEB entrepreneurship training on entrepreneurship intention, was investigated. According to the findings of the research, significant relationships were found between psychological capital and its sub-dimensions and entrepreneurship intention. Self-efficacy and hope seem to affect participants' intentions to become entrepreneurs. This situation seems to be compatible with the results of other studies in the literature (Boyd and Vozikis, 1994; Printing and 
Şeşen, 2012; Erkmen and Esen, 2012; Canbaz and Cankır 2013; Polatçı, 2014; Özdemir and Özgüner, 2016).

The findings show that both self-efficacy and hope from some demographic characteristics and psychological capital sub-dimensions affect the intentions of employees to be entrepreneurs. Accordingly, while durability and optimism do not significantly affect the intention of entrepreneurship, self-efficacy and hope dimensions affect the entrepreneurship intention positively and positively.

\section{Kaynakça / References}

Alparslan, A., Bozkurt, Ö. Ç., ve Aydoğdu, A. (2017). Etkin bir girişimcilik eğitim içeriği tartışması: Akademisyenler, girişimciler ve öğrenciler üzerinde saha araştırmaları. Mehmet Akif Ersoy Üniversitesi Uygulamalı Bilimler Dergisi (Makuubd), 1(1), 51-63.

Aksoy, B., Koçanci, M., ve Namal, M. K. (2019). Girişimcilik motivasyonu: Uygulamalı girişimcilik eğitimi katılımcıları örneği. Yönetim Ve Ekonomi: Celal Bayar Üniversitesi İktisadi Ve İdari Bilimler Fakültesi Dergisi, 26(1), 109-129.

Avey, J. B., Lynn, R., F., ve Nixon, D. R. (2012). Leader positivity and follower creativity: An experimental analysis. The Journal Of Creative Behavior, 46(2), 99-118.

Baandura, A. (2008). An agentic perspective on positive psychology. Positive Psychology: Exploring The Best In People, 1, 167-197.

Bockorny, K (2015) Psychological capital, courage, and entrepreneurial success. Phd Thesis, Bellevue Univ., Bellevue, Nebraska, Usa.

Bozkurt, Ö. Kalkan, A.Koyuncu, O. ve Alparslan, A. M. (2012). Türkiye'de girişimciliğin gelişimi: Girişimciler üzerinde nitel bir araştırma. Süleyman Demirel Üniversitesi Sosyal Bilimler Enstitüsü Dergisi, 15(1), 229-247.

Bozkurt, Ö. ve Erdurur, K. (2013). Girişimci kişilik özelliklerinin girişimcilik eğilimindeki etkisi: Potansiyel girişimciler üzerinde bir araştırma. Girişimcilik Ve Kalkınma Dergisi, 8(2), S. 5778.

Bryant, F. B., ve Cvengros, J. A. (2004). Distinguishing hope and optimism: Two sides of a coin, or two separate coins?. Journal Of Social And Clinical Psychology, 23(2), 273-302. 
Büyükyılmaz, O., Karakaya, A., ve Yıldırım, C. (2015). Girişimcilik eğitimi alan bireylerin demografik özellikleri açısından girişimcilik eğilimleri arasındaki farklar. Girişimcilik Ve Kalkınma Dergisi, 10(2), 105-125.

Chang-Hyun J. (2017). The Effect of psychological capital on start-up intention among young start-up entrepreneurs: A cross-cultural comparison. Chinese Management Studies, 11(4), 707-729

Chaudhary, R., Rangnekar, S., ve Barua, M. K. (2012). Relationship between occupational self efficacy, human resource development climate and work engagement. Team Performance Management, 18(7), 370-383.

Conger, J. A., ve Kanungo, R. (1987). Toward a behavioral theory of charismatic leadership in organizational settings. Academy of Management Review, 12, 637- 647.

Çolakoğlu, H., ve Çolakoğlu, T. (2016). Üniversitelerdeki girişimcilik eğitimi ile öz yeterlilik algısı ve girişimcilik potansiyeli ilişkisi üzerine bir saha araştırması. Sosyal ve Beşeri Bilimler Araştırmaları Dergisi, 17(37), 70-84.

Elert, N., Anderson, F. W., ve Wennberg, K. (2015). The impact of entrepreneurship education in high school on long-term entrepreneurial performance. Journal of Economic Behavior \& Organization, 111, 209-223.

Fayolle, A., ve Gailly, B. (2015). The impact of entrepreneurship education on entrepreneurial attitudes and intention: Hysteresis and persistence. Journal Of Small Business Management, 53(1), 75-93.

Goldsmith, A. H., Veum, J. R., ve Darity Jr, W. (1997). The impact of psychological and human capital on wages. Economic Inquiry, 35(4), 815-829.

Gorgievski, M. J., Halbesleben, J. R., ve Bakker, A. B. (2011). Expanding the boundaries of psychological resource theories. Journal Of Occupational And Organizational Psychology, 84(1), 1-7.

Güner, H., ve Korkmaz, A. (2016). Kosgeb uygulamalı girişimcilik eğitimigirişimcilik ilişkisi: Eğitim Alıp iş kurmayanlar üzerine bir araştırma. İş Ve Hayat, 2(4), 155-182. 
Harter, J. K., Schmidt, F. L., ve Hayes, T. L. (2002). Business-unit-level relationship between employee satisfaction, employee engagement, and business outcomes: A meta-analyses. Journal Of Applied Psychology, 87(2), 268-279.

Kumar, R., ve Sia, S. K. (2013). Employee engagement: Impact of occupational self-efficacy and affective commitment. Indian Journal Of Applied Psychology, 50, 93-102.

Hmieleski, K. M., ve Carr, J. C. (2008). The relationship between entrepreneur psychological capital and new venture performance. Frontiers Of Entrepreneurship Research, 28(4), 1-16.

Lopez, S. (2013). Making hope happen: Create the future you want for yourself and others. New York: Atria

Luthans, F. ve Youssef, C. M. (2004). Human, social and now positive psychological capital management: Investing in people for competitive advantage. Organizational Dynamics, 33(2), 143-160.

Luthans, F., Avalio, B. J., Avey, J. B. ve Norman, S. M. (2007a). Positive psychological capital: Measurement and relationship with performance and satisfaction. Personal Psychology, 60, 541-572.

Luthans, F., C. ve Youssef, B. A. (2007b) Psychological capital: Developing the human competitive edge, N, Oxford Press.

Luthans, F. ve Youssef, C. M., (2007), Emerging positive organizational behavior. Journal Of Management, 33, 321-349.

Luthans, F., ve Youssef-Morgan, C. M. (2017). Psychological capital: An evidence-based positive approach. Annual Review Of Organizational Psychology And Organizational Behavior, 4, 339-366.

Masten, A. S. ve Reed, M. G. J. (2002). Resilience in development. In (C. R. Snyder ve S. J. Lopez Eds.), Handbook Of Positive Psychology Oxford içinde (s. 74-88), Uk: Oxford University Press. .

Nabi, G., Linan, F., Fayollei A., Krueger, N. ve Walmsleyy, A. (2017). The impact of entrepreneurship education in higher education: A systematic review and research agenda. Academy Of Management Learning \& Education, 16(2), 277-299.

Namal, M. K., Koçanci, M., ve Aksoy, B. (2018). Kosgeb girişimcilik programı: Eleştirel bir değerlendirme. Akademik Hassasiyetler, 5(9), 93110. 
Öğe, S., ve Kaplan, M. (2017). Girişimcilik eğitiminde pozitif psikolojik sermayenin rolü üzerine bir değerlendirme. Balkan Ve Yakın Doğu Sosyal Bilimler Dergisi, 3(04), 28-33.

Önay, I , Ayas, S, Yaşar Uğurlu, Ö. ve Önay, M . (2017). Psikolojik sermaye ile girişimcilik niyeti ilişkisi. Gazi İktisat Ve İşletme Dergisi, 3(3), 5566.

Özdemir, P. (2016). Girişimcilik eğitimi ve üniversitelerimiz. Girişimcilik Ve Kalkınma Dergisi, 11(1), S. 224-240

Özdemir, P. (2017) Üniversitelerimizdeki girişimcilik eğitiminin farklı boyutlardan değerlendirilmesi. Girişimcilik Ve İnovasyon Yönetimi Dergisi, 6(2), 1-23

Özdemir, A. ve Özgüner, M. (2016). The effect of psychological capital on entrepreneurship: A study on university students. Journal Of $\mathrm{Hu}-$ man Sciences, 13(3), 5107-5121.

Özdemir, A., Özgüner, M., ve Alkiş, H. (2018) Üniversitelerde verilen girişimcilik eğitimi girişimci kişilik özelliklerini nasıl etkiler? Deneysel bir araştırma. Selçuk Üniversitesi Sosyal Bilimler Meslek Yüksekokulu Dergisi, 21(2), 430-447.

Pazarcık, Y. ve Aydın, E. (2015) Girişimcilik temelli ders tasarımının öğrencilerin girişimci eğilim ve davranışlarına etkisi: Üniversite öğrencilerine yönelik deneysel bir çalışma, Girişimcilik Ve Kalkınma Dergisi, 10(2), 126-146.

Rathi, N., ve Rastogi, R. (2009). Assessing the relationship between emotional intelligence and occupational self-efficacy and organizational commitment. Journal Of The Indian Academy Of Applied Psychology, 35, 93-102.

Sameer, Y. M., Mohamed, A. A., ve Mohamad, M. S. (2019). Antecedents of Psychological Capital: The Role Of Work Design. Journal Of Economics \& Management, 35, 124-149.

Seligmen, M. E. (1998). What is the good life. Apa Monitor, 29(10), 1-2.

Schyns, B. (2004). the influence of occupational self-efficacy on the relationship of leadership behavior and preparedness for occupational change. Journal Of Career Development, 30, 247-261. 
Schyns, B., ve Collani, G . V. ( 2002). A new occupational self-efficacy scale and its relation to personality constructs and organizational variables. European Journal of Work And Organizational Psychology, 11, 219-241.

Sisodia, R., Sheth, J. N., ve Wolfe, D. B. (2007). Firms of endearment: The societal imperative and the human corporation. Pearson Education.

Sinha, S. P., Talwar, T., ve Rajpal, R. (2002). Correlational study of organizational commitment, self-efficacy, and psychological barriers to technological change. Psychologia, 45, 176-183.

Snyder, C. R., Irving, L. ve Anderson, J. (1991). Hope and health: Measuring the will and the ways. (C. R.Snyder, D. R. Forsyth Ed.), Handbook Of Social And Clinical Psychology Elmsford, içinde (p.285-305) .Ny:Pergamon.

Stajkovic, A. D. ve Luthans, F. (1998a). Self-efficacy and work-related performance: A meta-analysis. Psychol. Bull. 124, 240-61

Stajkovic, A. D. ve Luthans, F. (1998b). Social cognitive theory and selfefficacy: Going beyond traditional motivational and behavioral approaches. Organizational Dynamics, 26(4), 62-74.

Sweetman, D., Luthans, F., Avey, J. B., ve Luthans, B. C. (2011). Relationship between positive psychological capital and creative performance. Canadian Journal Of Administrative Sciences/Revue Canadienne Des Sciences De L'administration, 28(1), 4-13.

Tang, Z., Dickson, P., Marino, L., Tang, J., ve Powell, B. C. (2010). The value of organizational ambivalence for small and medium size enterprises in an uncertain world. British Journal of Management, 21(4), 809-828.

Tekin, M. (1996) Girişimcilik: Kendi işini kurma ve işletme. Konya: Damla Ofset.

Titiz, T. (1999). Girişimcilik. İstanbul: İnkılâp Kitabevi.

Tugade, M. M., Frederickson, B. L., ve Feldman, B. L. (2004). Psychological resilience and positive emotional granularity: Examining the benefits of positive emotions on coping and health. Journal Of Personality, 72(6), 1161-1190.

Uluköy, M., Demireli, C. ve Kahya, V. (2013) Kosgeb girişimcilik eğitimi kurslarına katılan katılımcıların girişimcilik profiline yönelik bir alan araştırması. Girişimcilik Ve Kalkınma Dergisi, 8(2), 79-96. 
Uygun, M., Güner, E., ve Mete, S. (2018). Girişimcilik eğitiminin gençlerin girişimcilik motivasyonlarının gelişimindeki rolü. Yönetim Ve Ekonomi, 25(3), 879.

Youssef-Morgan, C. M., ve Luthans, F. (2015). Psychological capital and well-being. Stress And Health, 31(3), 180-188.

Zhu, Y., ve Wang, Y. F. (2011). The relationship between entrepreneur psychological capital and employee's innovative behavior: The strategic role of transformational leadership and knowledge sharing. In Advanced Materials Research, (p.691-696). Trans Tech Publications.

\section{Kaynakça Bilgisi / Citation Information}

Kahya, V. (2019). Psikolojik sermayenin girişimci olma eğilimine etkisi: kosgeb girişimcilik eğitimine katılan kursiyerler üzerine bir araştırma. OPUS-Uluslararası Toplum Araştırmaları Dergisi, 12 (18. UİK Özel Say1s1), 634-657. DOI: 10.26466/opus.587988 